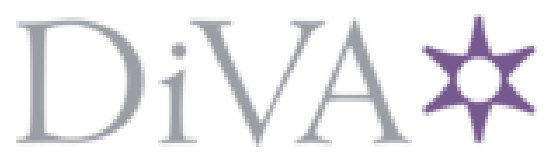

http://www.diva-portal.org

\title{
Postprint
}

This is the accepted version of a paper published in Journal of Organizational Change Management. This paper has been peer-reviewed but does not include the final publisher proof-corrections or journal pagination.

Citation for the original published paper (version of record):

Norrman Brandt, E., Kjellström, S., Andersson, A-C. (2019)

The future trip: A story of transformational change

Journal of Organizational Change Management, 32(7): 669-686

https://doi.org/10.1108/JOCM-09-2017-0358

Access to the published version may require subscription.

N.B. When citing this work, cite the original published paper.

Permanent link to this version:

http://urn.kb.se/resolve?urn=urn:nbn:se:hj:diva-45724 


\title{
The future trip: a story of transformational change
}

\author{
Abstract \\ Purpose - The study of successful transformational change processes in organizations has \\ been limited. The aim was to understand a change process and the type of change that \\ occurred in a pharmaceutical company in Sweden 2005-2014. \\ Method - An interactive research design was used, and semi-structured interviews were \\ conducted with 19 individuals, asking about their views on the change journey. Meetings and \\ dialogue with leaders from the organization also took place. Observations from feedback \\ meetings with leaders were included in the analysis. The results were analysed using a time- \\ ordered display identifying key events, interpreted by a theoretical lens determining the type \\ of change over a period of 10 years.
}

Findings - This was a transformational change caused by external pressure, supported by visionary and transparent leadership, collaborative methods aiming at broad involvement, and systemic understanding. The results indicated a $40 \%$ increase in productivity and altered organizational design and culture. Sense-making activities, persistent adoption of quality improvement tools, dispersed power, and sequential change activities underpinned the success.

Practical implications - The results provide insight into the processes of transformational change. Change leaders were provided with knowledge, inspiration and insight when facing transformations.

Social implications - Increased prevalence of transformational change calls for new organizational competencies and altered roles for leaders and employees. There is a need for new ways of developing competence and new recruitment policies for leaders. 
Originality/value - This case presents unique empirical evidence of a successful cultural transformation led by a leader using post-conventional principles.

Keywords: Change process, Post-conventional principles, Innovation, Transformational change

Introduction

For an organization and its leaders and employees, the ability to master change is vital for economic, welfare, health and work environmental reasons (Iveroth and Hallencreutz, 2015; Kegan and Lahey, 2009; Kotter, 2007). Many industries today must rethink how they operate and organize (Lee et al., 2012). External factors such as technological development, government regulations, changing customer demands, and increased competition are often mentioned as antecedents to transformational change (Lant et al., 1992; Lee et al., 2012; Pettigrew, 1987).

Research reviews on numerous improvement projects show that $70 \%-80 \%$ of all change initiatives fail (Burnes, 2009; Hallencreutz, 2012). Studies of organizational cultural changes show that $90 \%$ of these change efforts never reach their targets (Burnes, 2011). Research highlights several different causes of failure, but some of the most important are lack of attention to corporate culture, employee resistance to change, and the leader's lack of ability to drive change (Hallencreutz, 2012; Kezar and Eckel, 2002; Newhouse and Chapman, 1996). Research reviews show that few descriptions of transformational change processes exist (Lee et al., 2012), and there is a need for more knowledge on the dynamics of pace, sequence and linearity of transformational change (Amis et al., 2004).

The case described in this article was chosen for three reasons. First, the change process was successful (Cameron et al., 2003; Södergren, 2016) as measured by an improvement in a number of key performance indicators, such as employee satisfaction, 
productivity and engagement (Sandell et al., 2013). It seems meaningful to identify the success factors in such a process and build on its strengths (Cooperrider and Whitney, 2005).

The culture was altered as well as the organizational design over the period 20052014. Because cultural change is considered challenging and rare (Burnes, 2011), it was interesting to look closely at the process of change and analyse what success factors were present. Second, one of the site leaders (the managing director from 2010 to 2014) adopted post-conventional principles at work (Norrman Brandt et al., 2019; Torbert et al., 2004). A leader using post-conventional principles has a visionary long-term view of the organization, looks outside own industry for trends and ideas, challenges the current system, negotiates with superiors if needed, involves multiple stakeholders and seeks out feedback for own personal development (Joiner and Josephs, 2007; Torbert et al., 2004). Empirical research has shown that leaders with post-conventional action logics (Torbert et al., 2004) are more successful in driving transformational change, but they are rare (Kjellström and Andersson, 2017; Rooke and Torbert, 1998). This case provided a unique opportunity to study a such change process. Third, this study was made possible by a mutual interest between the organization and the researchers in gaining a deeper understanding of the mechanisms behind the success, the rich data available addressing the change process and the key events driving it, and the access to numerous employees who had been present during the change and could tell their story.

When analysing a change process, identifying a suitable framework is a challenge because there are several ways of classifying change. In this case, the scale and scope and the rate of occurrence of change are highly relevant, because these parameters capture contextual factors in a new era where old truths and rules seem to be replaced by new capabilities (Crocitto and Youssef, 2003; Marshak, 2002). It was also highly appropriate to determine whether this change process could be regarded as a transformational change (Greenwood and Hinings, 1993; Kezar and Eckel, 2002; Pettigrew, 1987). Many organizations have to 
challenge old assumptions and truths in order to stay competitive (Crocitto and Youssef, 2003; Hamel, 2006; Lee et al., 2012). A transformational change entails a fundamental change of culture and assumptions, required in many organizations due to external changes (Lant et al., 1992; Lee et al., 2012) and, therefore, interesting as a phenomenon to study in today's complex and turbulent environment.

\section{Change types}

The language of change is a challenge because many of the theories and concepts originate from a context that has changed distinctively (Marshak, 2002). In many ways, the way that change is described is also contradictory (By, 2005; Burnes, 2009), and the interpretation of change theories depends much on the interpreter's way of making sense and their background and area of knowledge (Rosenbaum et al., 2018). In this study, the aim was to describe a change process over time, so some categorization of change was needed. Change theories have been classified in three ways: scale and scope, rate of occurrence, and how change comes about (By, 2005; Senior and Swailes, 2010). Scale and scope and the rate of occurrence have been combined in a matrix based on Marshak (2002) and Nadler and Nadler (1998). The matrix depicts four types of change and has been used as a roadmap for diagnosing and discussing change (Figure 1). Different approaches may be necessary for dealing with these different change situations. 


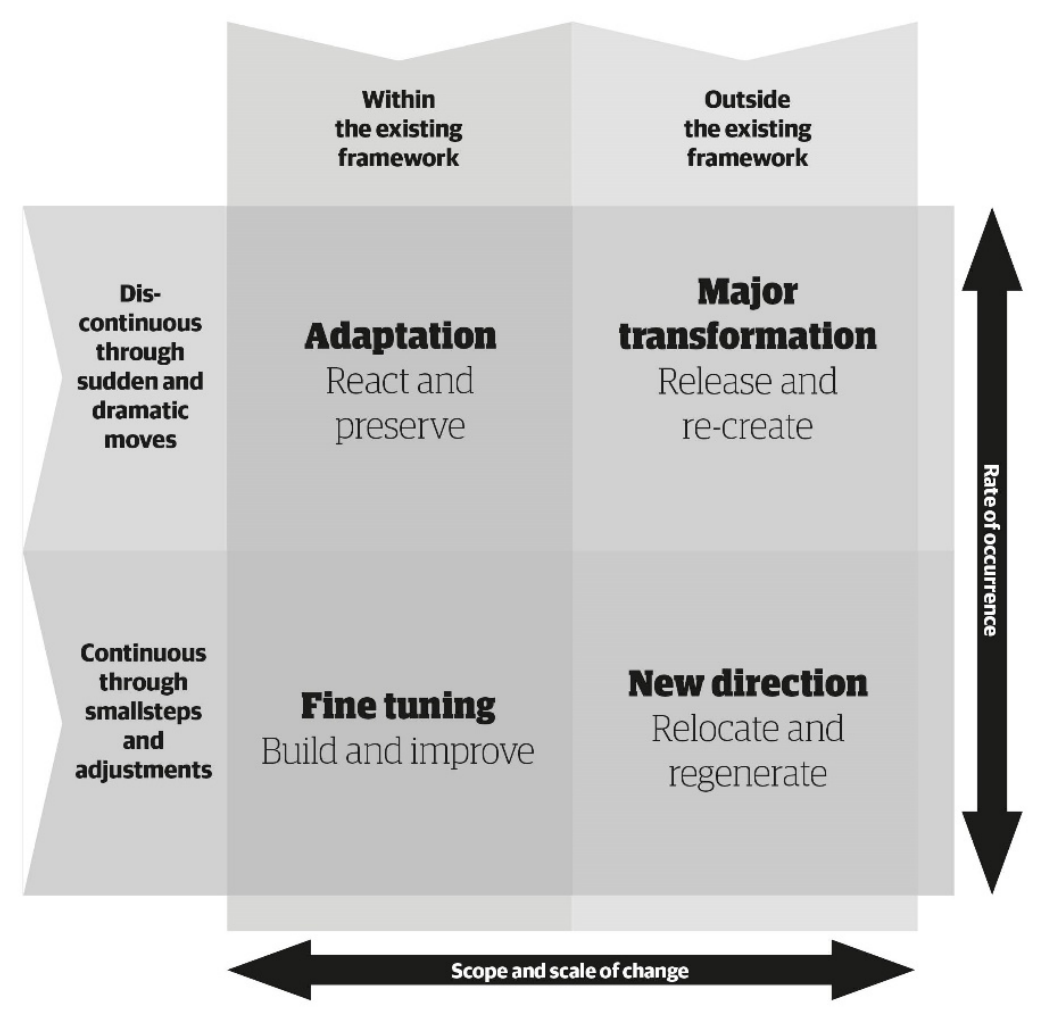

Figure 1. Four different types of change. Source: Based on Marshak (2002) and Nadler and Nadler (1998).

Fine tuning in the lower left corner of Figure 1 is a type of change that is both expected and allows the organization to stay within its current frames. Adjustments are small and stepwise within an existing framework. Most organizations are familiar with this type of change, which is characterized by continuous improvements on the job on a regular basis.

Adaption occurs when external factors put pressure on the organization. It does not mean that the business will have to change, but the external pressure and dramatic consequences apply pressure to reorganize. The organization still operates within the existing framework but may have to scale up or down with dramatic speed.

New direction represents change that is not sudden or unexpected but still forces the organization to handle a new situation outside the current framework. This kind of change is 
often triggered by a major decision from key stakeholders, or by changed legislation or deregulation. When an organization is confronted with a change like this, it calls for transformation of the organization and culture.

The fourth and most radical type of change is termed major transformation, which indicates a change that comes with speed and with a dramatic effect on the core of the organization. This kind of change can be caused by new technology affecting a mature business such as photography and media (Iveroth and Hallencreutz, 2015). It can also be caused by a profound disruptive external event.

When regarding these categories of change, it becomes clear that they challenge the organization to varying degrees, and some of the changes can be described as transformational change because they require a shift in organizational culture (Kezar and Eckel, 2002). Transformational change is described in the next section, and the types of change described in the matrix built on Marshak (2002) and Nadler and Nadler (1998) are matched with the criteria for transformational change to determine which of the different types of change meet those criteria.

\section{Transformational change}

Among the types of changes an organization may have to handle, transformational change is the most challenging and lengthy one (Greenwood and Hinings, 1993; Newhouse and Chapman, 1996; Weick and Quinn, 1999). Compared with less radical changes, transformational change affects the entire organization (Balogun and Hailey, 2008; Lee et al., 2012). It is described as a fundamental change in culture, practices and underlying assumptions of the organization (Balogun and Hailey, 2008; Greenwood and Hinings, 1993; Kezar and Eckel, 2002; Pettigrew, 1987). Several perspectives have to be considered, and the balance between context, content and process is crucial (Pettigrew, 1987). Although the role 
of leadership must be balanced by other aspects, it seems to be of high importance in transformational change because it must engage and include all members of the organization (Amis et al., 2004; Kezar and Eckel, 2002; Newhouse and Chapman, 1996; Pettigrew, 1987). Successful transformation seems to occur through lengthy, iterative processes that cannot be described as linear (Amis et al., 2004; Greenwood and Hinings, 1988; Newhouse and Chapman, 1996; Weick and Quinn, 1999). Newhouse and Chapman (1996) described the importance of dialectic process, balancing new and old interpretive schemes to make change stick. The presence of an internal trusted change leader seem to increase the chances of making change stick (Newhouse and Chapman, 1996; Rosenbaum et al., 2018). A review article of organizational transformational change in health care and other industries identifies antecedents, processes and outcomes of transformational change (Lee et al., 2012). Fifty-six organizations met the criteria of multifaceted, discontinuous and dramatic/full-scale change, and most of the changes occurred after 1990. Few examples describing the processes of transformational change were found. Portrayals of the complexity in the processes, including transformation in structures and relationships affecting units, roles and levels of hierarchies, were rare (Lee et al., 2012). Studies of change are often limited because few academic researchers studying change collect time-series data (Amis et al., 2004; Pettigrew, 1998). Most studies use short time frames and define the period of investigation as the period when data were collected and available (Kezar and Eckel, 2002; Lant et al., 1992).

The pace, linearity and process of radical change has been subject to different views among scholars, and empirical support is still needed in these domains (Amis et al., 2004). A rapid pace of change has been considered by some scholars to be necessary to achieve radical transformations and overcome inertia (Romanelli and Tushman, 1994; Tushman and Romanelli, 1985). However, others argue that radical changes have to be driven through gradual steps in order to make sense and achieve organizational commitment (Amis et al., 
2004; Pettigrew et al., 1992). The sequence of change also plays an important role for the outcome, starting with vital parts of the organization showing examples of change and providing a strong symbolic meaning and signal (Amis et al., 2004; Pettigrew et al., 1992).

The role of the leader is often mentioned as critical for successful change (Kezar and Eckel, 2002; Newhouse and Chapman, 1996). In an article on transformational change in higher education institutions, Kezar and Eckel (2002) contended that senior administrative support, collaborative leadership, vision, and design were all strategies related to transformational change. Pettigrew $(1985,1987)$ stresses that leadership is only one ingredient of change, and the context and content of change also plays an important role. The balance between context, the why of change, the content, the what of change and the process, the how of change must be considered to understand a transformation (Pettigrew, 1987).

Transformations are difficult to effect, the outcome is difficult to predict, and there has to be a good reason for undertaking them (Balogun et al., 2016). They involve all members of the organization and must be planned and driven with close consideration of multiple perspectives (Amis et al., 2004; Kezar and Eckel, 2002; Pettigrew, 1985). Given the scarcity of studies on transformational change processes, empirical cases such as this study can contribute to close the gap between theoretical knowledge and practice and should be helpful for practitioners and scholars.

The purpose of this article is to describe and analyse what types of change occurred during a 10-year process, and to determine if and how any of the change phases met the criteria for transformational change. 


\section{The case/setting}

The organization is a pharmaceutical plant with 219 employees in 2015 . The plant is part of a global organization founded in 1849 in the United States. In 2012, there were 88,000 employees at 190 sites worldwide (Seller and Davis, 2013). The company was established in Sweden in 1954, and has grown with acquisitions but has also sold or transferred units during 2006-2008. Today, the Swedish branch has about 450 employees located in a marketing and sales unit near Stockholm and in a plant located $100 \mathrm{~km}$ south of Stockholm.

Although quite small, the plant is mentioned as one of the world's leading and most modern and efficient production facilities within a corporate setting. Leaders from the plant were contributing authors to an OPEX (operational excellence) anthology (Friedli et al., 2013) and described the plant as having managed to create a culture of sustainable change, increased productivity, employee satisfaction, employee health, willingness to contribute in innovative processes, and common problem solving (Sandell et al., 2013). There were some tangible results (Sandell et al., 2013). Each employee produces 24 improvements per year, increased from 8 a few years ago. Company surveys show that $81 \%$ of the employees rate the positive climate and high commitment ( $76 \%$ for the company globally). Absence (when sick) was $2.5 \%$, and the productivity has increased by $40 \%$, while the level of stress has decreased (Sandell et al., 2013).

The factory has received the International Society of Pharmaceutical Engineers prize, the Factory of the Year award in the category of Operational Excellence 2011, and awards for environmental work. The plant received the Change Management Award for Best Change Project at the 2012 Change Management Forum in Stockholm. 


\section{Methods}

This was a qualitative single case study (Eisenhardt and Graebner, 2007; Yin, 2003) with an interactive research design (Svensson et al., 2002). Interactive design is a form of action research whereby two active partners contribute (the researchers and the organization) with clearly defined roles and a purpose to create common knowledge (Ellström, 2007). The case was selected through purposive sampling because it represents a successful cultural transformation. During parts of the process, it was led by a leader adopting post-conventional principles (Norrman Brandt et al., 2019; Torbert et al., 2004) and offered an opportunity to track a change process over a 10-year period. The study is based on data from interviews and observations of meetings, triangulated with archival data. Inductive and deductive logic are used (Eisenhardt and Graebner, 2007) and the sense-making strategy used refers to an alternate template strategy (Langley, 1999) because it includes several alternative interpretations of the same event. The participants expressed contrasting interpretations and stories of phases in the change process.

The research team included one $\mathrm{PhD}$ student $(\mathrm{ENB})$ and two senior researchers $(\mathrm{SK}$, ACA). Two team members (ENB, ACA) have extensive professional experience with change work. All members of the research team were involved in the planning of the study. One researcher (ENB) had worked with the organization as a consultant during the period 20052011. During 2011-2014, no consultancy work was done but contact with the site manager led to the start of the research project in 2013.

\section{Participants and data collection}

The study was based on interviews for which participants were selected to represent a broad sample within the organization. It is also based on data from four interactive meetings with a leader forum gathering managers and team leaders at the site. The interviewees were chosen through a purposive sampling strategy, aimed at selecting participants with diverse 
characteristics from the organization. The selection was made in cooperation with an appointed contact person for the research project. Leaders attending the leader forum also had a chance to suggest people with different views on the change process, all with the aspiration to get a broad and diverse selection of interviewees. The contact person asked the participants, and the research group provided an information letter giving details of the study design, research ethics, and requirements in terms of time for the participating staff. All participants except two who had been recruited for their former experience with transformations, had worked more than 8 years in the plant, some much longer, up to 27 years. The participants with least experience in this sample had worked there for 5 years (Tables 1 and 2). 
Table 1. Characteristics of the participants in the interviews

\begin{tabular}{lll}
\hline Participants & Educational level & Role in organization in 2015 \\
\hline $\begin{array}{l}\text { 12 women aged 39-60 years } \\
\text { (average, 47 years) }\end{array}$ & 4 upper secondary level & 5 managers, 1 former (had left) \\
& 6 graduate level, 2 PhDs & 4 specialists \\
7 men aged 39-58 years (average, & 4 upper secondary level & 2 organizational developers \\
48 years) & 2 graduate level & 2 managers \\
& 1 PhD & 1 team leader \\
& & $\begin{array}{l}1 \text { organizational developer, } 1 \\
\text { former (had left) }\end{array}$ \\
& 2 specialists \\
\hline
\end{tabular}


Table 2. Meetings with the leader forum

\begin{tabular}{|c|c|c|}
\hline Date & Focus of meeting & Participants \\
\hline November 3, 2014 & $\begin{array}{l}\text { Dialogue on goal, purpose and } \\
\text { collaboration in the research study }\end{array}$ & 16 leaders, 2 researchers \\
\hline January 26, 2015 & $\begin{array}{l}\text { Ideas on topics for interviews to come, } \\
\text { ideas on people for interview, } \\
\text { reflections on changes made and } \\
\text { challenges forward }\end{array}$ & 15 leaders, 3 researchers \\
\hline August 24, 2015 & $\begin{array}{l}\text { Feedback on preliminary results from } \\
\text { interviews made in February to June. } \\
\text { Reflections on how the results could } \\
\text { be used for future learning in the } \\
\text { organization }\end{array}$ & 10 leaders, 3 researchers \\
\hline September 12, 2016 & $\begin{array}{l}\text { Feedback from the thematic analysis. } \\
\text { Face validity tested; was there } \\
\text { anything missing or anything that did } \\
\text { not seem correct }\end{array}$ & 12 leaders, 3 researchers \\
\hline
\end{tabular}

Two kinds of data were collected in this study: from the interviews and observational notes. Interviews were conducted by ENB during 2015. A semi-structured interview guide with questions about key events during the change journey and views on change, leadership, and participation were used. The questions targeted the years 2005-2014 as the time span for change. The interviews were carried out as face-to-face meetings at the workplace. The interviews lasted 50-75 minutes and were audio recorded and transcribed.

Observational notes were collected from workshops, meetings and seminars where the researchers were invited to attend. During 2013-2016, the authors (ENB, SK and ACA) participated in and arranged five workshops with a leader forum (one before the research contract, four after the contract in 2014-2016). Additional data were collected by reading about the company in book chapters in an operational excellence anthology, on the company's webpages, and in articles published in newspapers. 
Analysis

All data in the study were analysed using a time-ordered display according to Miles and Huberman (1994), which allowed the chronological flow and the process to appear clearly while displaying key events (Langley, 1999; Van de Ven and Poole, 1995). The steps taken to build a time-ordered display were

1. Thorough reading of the interview transcripts by three of the authors (ENB, SK, ACA) identified key events (Miles and Huberman, 1994) in the change journey. All notes from the workshops, meetings and written material were also analysed.

2. The key events were listed and all data re-read to find additional key events (ENB, SK, ACA).

3. Key events were organized according to a timeline (Miles and Huberman, 1994) and written up as a narrative (Reissner, 2011; Taylor, 1999). Contrasting views from the case study were discussed (Yin, 2003) to analyse rival explanations and thus strengthen the internal validity (ENB, SK, ACA).

4. As a final step, the theories of Marshak (2002) and Nadler and Nadler (1998), as combined in Iveroth and Hallencreutz (2015), were applied to the key events to distinguish different types of changes. The definition of transformational change (Kezar and Eckel, 2002; Pettigrew, 1987) was used to interpret the overall change process. The analysis was discussed to reach consensus (ENB, SK, ACA). In the Results section, the tables demonstrate the empirical support for the theories (Eisenhardt and Graebner, 2007).

\section{Methodological considerations and reflexivity}

When using retrospective data, there is always a risk of errors and omissions (Langley, 1999), and this was counteracted with several strategies. Multiple data sources of evidence were used, such as interviews and media articles, but also using the main author's 
memories from involvement as a consultant from 2005 to 2010. The diversity of the interviewees created a purposive sample and rich data. The diversity of views (including persons openly critical and less impressed with the change design and leadership) of the change process contribute to establish the validity of the results, and interviews were also triangulated with media material to ensure construct validity (Yin, 2003). In addition, the data analysis and results were fed back and presented to the people at the site throughout the analysis process, which created face validity used to estimate the trustworthiness of studies (Elo et al., 2014). One person was primarily responsible for the interviews (ENB), but the others carefully followed up on the whole analysis process and discussed divergent opinions concerning empirical (SK, ACA) and theoretical (ACA, SK) interpretations. Two of the authors had no previous relationship with the organization. The main author of this article assisted regularly as an organizational consultant from 2005 to 2010. From 2011 to 2015, no consultancy work was done. The earlier contact with the organization contributed to validate data, because the main author could validate some of the events having been present when they occurred. An informed consent process was initiated with all participants to secure integrity, autonomy and confidentiality. A legal agreement was drawn up stating that we, as researchers, have the right to publish papers on the change process, but would have to secure agreement from the organization if using the company's name in articles.

\section{Results}

The analysis resulted in three distinct time periods demonstrating different kinds of changes, according to Marshak (2002) and Nadler and Nadler (1998) (Table 3). Features of transformational change were found in the last period of analysis. 
Table 3. Time periods and different kinds of changes

\begin{tabular}{|c|c|c|c|}
\hline Time period & Key events & $\begin{array}{l}\text { Type of change (Nadler and } \\
\text { Nadler, 1998; Marshak, } \\
\text { 2002) }\end{array}$ & $\begin{array}{l}\text { Transformational change } \\
\text { (Pettigrew, 1987; Kezar and } \\
\text { Eckel, 2002) }\end{array}$ \\
\hline 2005-2009 & $\begin{array}{l}\text { New manager; decision to } \\
\text { build new plant; new head } \\
\text { of quality; integration of } \\
\text { production and quality; } \\
\text { system overview; } \\
\text { downsizing; quality } \\
\text { improvement toolbox; } \\
\text { preparation for transfer to } \\
\text { new plant; collaboration } \\
\text { with corporate expertise }\end{array}$ & $\begin{array}{l}\text { Fine tuning: expected } \\
\text { change within existing } \\
\text { framework }\end{array}$ & $\begin{array}{l}\text { Did not fulfil the criteria for } \\
\text { transformational change } \\
\text { because organization still } \\
\text { operated within existing } \\
\text { framework }\end{array}$ \\
\hline 2009-2011 & $\begin{array}{l}\text { Inauguration of new plant; } \\
\text { merger with another } \\
\text { company; change of CEO in } \\
2010 \text {; downsizing } 2010 ; \\
\text { critical event (lack of water } \\
\text { when scaling up } \\
\text { production); handled by } \\
\text { employees when } \\
\text { collaboration for a solution }\end{array}$ & $\begin{array}{l}\text { Adaption: unexpected } \\
\text { disruptive events occurred } \\
\text { when moving to new plant } \\
\text { and scaling up; still within } \\
\text { existing frameworks }\end{array}$ & $\begin{array}{l}\text { On the path to } \\
\text { transformational change } \\
\text { introducing new ways of } \\
\text { working but not a fully } \\
\text { transformed culture }\end{array}$ \\
\hline 2011-2014 & $\begin{array}{l}\text { Call for } 50 \% \text { increase in } \\
\text { productivity; call for world- } \\
\text { leading standard; innovation } \\
\text { project launched (the Future } \\
\text { Trip); support from external } \\
\text { consultant in setting up the } \\
\text { innovation team; new } \\
\text { organization (from } \\
\text { departments to flow-based } \\
\text { organization); new } \\
\text { recruitment policy } \\
\text { established (from formal } \\
\text { merit system to suitability } \\
\text { for a role); shift of power } \\
\text { (bottom up) }\end{array}$ & $\begin{array}{l}\text { New direction: somewhat } \\
\text { expected but changing the } \\
\text { culture and the basic } \\
\text { assumptions about several } \\
\text { procedures in the } \\
\text { organization. The } \\
\text { organization went outside } \\
\text { earlier cultural frameworks }\end{array}$ & $\begin{array}{l}\text { This period fulfils the } \\
\text { criteria for transformational } \\
\text { change, questioning earlier } \\
\text { underlying assumptions } \\
\text { about how to organize, } \\
\text { roles, power. A new focus } \\
\text { on external factors and } \\
\text { important processes }\end{array}$ \\
\hline
\end{tabular}

\section{The change journey 2005-2009}

Our scope starts in 2005, which was a significant year for the plant, because a new manager with a strong link to the corporate world entered the stage and soon decided on a site suitable for the establishment of a new plant. The decision was made as a result of his discovery of a culture with strong commitment, knowledge in biotech production, and sense of quality. 
In 2005, the plant was organized in a functional manner; every department had its own budget and looked after issues close to their own functional challenges. Little attention was paid to overarching issues for the plant. The decision to build a new plant opened up the opportunity for change; an overview of the system began so that all processes could and were scrutinized.

From 2005 to 2009, two waves of downsizing took place. As it was conveyed, the downsizing was not too dramatic because people close to retirement were offered favourable severance packages. Although described as somewhat undramatic, the interviewees indicated an awareness of the risk of being made redundant, and some people expressed a sense of uncertainty about their status and security.

The quest for shorter lead times in production called for more collaboration across units. "The external demands on productivity forced people to adopt a new logic, the voice of the product meaning departments have to adopt a holistic view." (I15) A new head of quality was hired to integrate quality with production as a first step towards a more holistic and collaborative view.

The "silo" concept was challenged, and some of the downsizing was a result of the system overview and examination if production could be achieved with fewer people across departments.

There was an overall focus on improvement work introducing Six Sigma and training people in this method. Improvement work according to LEAN was also adopted but interviewees and meetings with managers from this period emphasize that it was used more like a toolbox. People learned and used the different improvement tools as they were told to, but few realized why and when the tools were specifically useful. When key people left, the energy to use the tools faded. 
The holistic perspective that helped people understood why and when to use different tools came a little later, with several indications pointing to 2012-2013, but the introduction of improvement tools was a beginning. "We were clearly on an instrumental level before 2009 , but from then on we got another approach and understanding," one of the top leaders explained in a meeting about the change journey in 2013.

During the planning for the new site, skilled people were released from ordinary production to help build and plan for the new site. The transfer of methods and processes for the new site took some effort and experts from other corporate sites came and lived in the town during the 3-4 years it took to build the new plant. "We had an amazing opportunity to train our transcultural skills, there was a lot of conflict during the process but at the end of the day we all learned and got the site up and running," a top manager stated. She meant that having to consider different perspectives from people with other cultural backgrounds increased the capacity to collaborate, something much needed in the following years when collaboration and mutual problem solving were key.

\section{Change analysis 1st period: 2005-2009}

The period from 2005 to 2009 saw tangible changes such as downsizing and preparations for transition to the new site. The change started in two departments (quality and production) and demonstrated an example of a more collaborative way of working (Amis $e t$ al., 2004). The start of radical change profits from a sequence of change that allows the rest of the organization to see an example (Amis et al., 2004). Different quality management tools were used, and changes were done incrementally and stepwise. The quality improvement work was performed within existing frames in the organization, even though there was an increased focus on cross collaboration over functional boarders. The external pressure caused by preparation for entering a new facility with new possibilities and demands put the organizational structure to the test, and a more rational and efficient design emerged in this 
process. The changes were not unexpected or sudden and nothing happened that threw the organization outside existing frames, although the culture and way of working did begin to change. Thus, it can be considered as fine tuning (Table 4). 
Table 4. Change analysis according to Marshak (2002) and Nadler and Nadler (1998) matrix with features of fine tuning matched with findings from the 1st change period (2005-2009)

\begin{tabular}{ll}
\hline Features of fine tuning & Findings from the study \\
\hline Continuous & $\begin{array}{l}\text { Small improvements on a daily basis using quality } \\
\text { improvement tools such as LEAN tools, Six Sigma, and } \\
\text { others }\end{array}$ \\
Within existing framework & $\begin{array}{l}\text { Changes and improvements made allowed the organization } \\
\text { to stay within the existing structure and culture }\end{array}$ \\
Stepwise & $\begin{array}{l}\text { Small steps aimed at new ways of collaboration and } \\
\text { efficiency were made in limited parts of the organization }\end{array}$ \\
Small adjustments & $\begin{array}{l}\text { No radical changes took place although preparations for a } \\
\text { bigger change were made (move to a new plant) }\end{array}$ \\
\hline
\end{tabular}

\section{The change journey 2009-2011}

Two big structural events took place at the plant in 2009. First, the merger and acquisition with another pharmaceutical company meant a structural change at the beginning of 2009, reflecting the corporation's ambition to grow stronger within the biotech area. The Swedish site gained eight sister companies, a wider group to relate to after being a solitary organization in the area. The entry of several new plants within the corporate family challenged ways of thinking and organizing the work and contributed to new perspectives on manufacturing and culture.

Second, the inauguration of the new plant drew attention to the site from the media, politicians, and top management. The plant had been built to deliver a wider range of products and opened up new business opportunities such as license production for other companies.

Several unexpected events occurred when transferring into the new plant. The new plant had a much higher capacity and scaling up production put collaboration, innovation skills and flexibility to the test. One specific event that occurred was a shortage of water for 
the expansion of production that took place 2010. The site leader declared that the management team was depending on collaboration and knowledge from employees in the plant: "If they could not solve it, who could? The management team definitely could not have solved this unexpected and crucial situation." (I2)

Such events strengthened the confidence among the employees that they could handle unexpected crisis by collaboration and using their shared experience. Many brains think better than one was a phrase used from management to support the idea that there was a lot of inherent wisdom among the people at the plant. The sense of collective goals as being necessary, instead of the "siloed" functional thinking that prevailed a few years earlier, was beginning to settle in. Although a positive period, views from the interviews also talk about a heavy workload. A change of site leader occurred in 2010 while the former head of quality took on the role of site leader for the Swedish site. The choice of leader was regarded as a statement for a more involved and less traditional leadership style. In 2010, 25 people left the plant because of the new ways of working.

Strong functional leaders had been hired but when the organization went towards involvement and distribution of power, some leaders did not match the requirements and left as did some of the experts who did not approve of the new way of working and organizing. (I2)

Everybody in the organization was involved in the search for every possible way of improving work processes and avoiding waste.

\section{Change analysis 2nd period: 2009-2011}

The definition of adaption requires that external, unexpected and maybe sudden events appear. The situation at the plant was subject to external events on a corporate level when there was a decision to strengthen the biotechnical capacity by merging with another biotechnical company. The call for efficiency challenged the set of structures and systems that 
had been used (Greenwood and Hinings, 1993). Employees took on greater responsibility and solved critical situations by collaborating. The pace of change was high, with several events occurring at different levels, and can therefore be considered as adaption (Table 5). 
Table 5. Change analysis according to Marshak (2002) and Nadler and Nadler (1998) matrix with features of adaption matched with findings from the 2nd change period (2009-2011)

\begin{tabular}{ll}
\hline Features of adaption & Findings from the study \\
\hline External pressure & Moving into new plant with another company \\
Dramatic & $\begin{array}{l}\text { Unpredictable event when scaling up production (water } \\
\text { shortage) }\end{array}$ \\
Scaling up/down & 18 times larger production volume and license production \\
Non-predictable & $\begin{array}{l}\text { Disruptive circumstances when moving biotech production } \\
\text { into new plant }\end{array}$ \\
&
\end{tabular}

\section{The change journey 2011-2014}

In 2011, the plant was faced with a new message. The new site leader realized that there had to be a $50 \%$ cost reduction in one of the products within a time span of 5 years because of competition. This situation could not be solved within existing frames. This meant a restructuring process, including a change in interpretative schemes. The hierarchical pyramid was turned upside down, calling for support and participation from all employees. The management team engaged a consultant to support the transformation needed. Areas of improvement were identified, and an innovation project was set up recruiting 22 individuals with the necessary qualities and motivation. Candidates for the project were invited and selected regardless of hierarchical position or level of education.

\section{The Future Trip}

The innovation project was called the Future Trip by its members and got direction and support from the site leader and her team to work in four streams or innovation groups, with 5-6 people in each. The topics for the streams were leading and steering, new products, communication and branding, and competency and staffing. The people who were part of the project spent $10 \%-20 \%$ of their working time on the project. 
The groups presented their ideas and findings during company days twice a year, where all employees were invited for discussion and input. The reactions to the different sense-making activities were positive, although some were critical of some of the activities at the company days. "It sometimes felt like a playhouse" (I9) was how one of the interviewees put it when referring to creative and playful exercises with the objective of activating creativity.

\author{
We used creative methods engaging both sides of the brain, some liked it and some did not \\ understand how playing with metaphors could be useful for the enhancement of work processes. (I8)
}

The mandate to decide how to solve the issues given were described as somewhat unreal.

Did the manager really mean we could decide how to do this? We initially reacted with passivity and disbelief, but when realizing we had a real mandate, we became creative and engaged. (I8)

A first suggestion from the leading and steering stream was to reorganize the plant to put the product in focus, which meant a new way of working. The emerging way of working was later named "Go with the flow". Today the plant is organized in such a manner, but there were several smaller steps and pilots on along the road.

A gradual transition to a flow-based way of working took place through several means, supporting the product's journey through the system. One measure was to create a new kind of leadership role responsible for the coordination of production. A more crossfunctional and collaborative way of working within the entire organization emerged in 2012 and resulted in a permanent new structure whereby old departments and structures were replaced with mixed competency groups with more flexible roles.

The site leader emphasized the importance of a clear mandate to come up with ideas and solutions. Her focus was to pick the right people for the task and release power and 
control. In many ways, the traditional hierarchy was turned upside down. The results from the different streams were launched as pilots, to try out the sustainability of the new innovations on a smaller scale. These pilots did not challenge or threaten the basic functions of the operations. "We worked under the radar to test new ideas on a smaller scale" (I9), a team leader explained as a way of avoiding too much negotiation with trade unions when altering roles, or having too much bureaucratic work before knowing if an innovation was worth making permanent. The stability of the plant was sustained throughout the somewhat experimental and innovative period, and the corporate management team felt confident with the results and deliveries. The ambition and requirement from the corporate level was to obtain world-leading standards in all aspects of the plant.

At the end of this period, the plant was totally reorganized on a more permanent basis. Now, they are organized around the products, the workflows, in mixed groups with different competencies. A coaching and people-orientated leadership with a solid understanding of the whole system is now established.

\section{Change analysis 3rd period: 2011-2014}

The definition of new direction contains elements that throw the organization out of its current frames. It is often caused by a major decision from key stakeholders, and it requires rethinking and reframing the organization. All these elements were present in the third period. The need to dramatically increase productivity was the starting point for the Future Trip. The effects of the work within the Future Trip soon affected the organization and the way it was led. Collaboration across units, comprehension of the common challenges and tasks, distribution of responsibility, all came together as building blocks of a cultural transformation (Table 6). 
Table 6. Change analysis according to Marshak (2002) and Nadler and Nadler (1998) matrix with features of new direction matched with findings from the 3rd change period (2011-2014)

\begin{tabular}{ll}
\hline Features of new direction & Findings from the study \\
\hline Reframing the organization & New organizational design from functional to flow-based \\
External pressure & $\begin{array}{l}\text { A } 50 \% \text { decrease in costs over } 5 \text { years was to be } \\
\text { accomplished }\end{array}$ \\
New organizational culture & $\begin{array}{l}\text { Turning hierarchy upside down with the Future Trip } \\
\text { Rethinking old assumptions }\end{array}$ \\
& $\begin{array}{l}\text { Roles and responsibilities were altered (all employees } \\
\text { responsible) }\end{array}$ \\
\hline
\end{tabular}

\section{Comparing transformational change with the Marshak and Nadler and Nadler} matrix

Using two theoretical frames as analytical tools for this change process, we looked at the Marshak (2002) and Nadler and Nadler (1998) matrix to determine if the types of changes made within the site met the criteria of transformational change. At the end of the study period, we concluded that the definition and criteria for transformational change were met. New direction meant a profoundly new way of organizing, working and thinking. During the final period studied (2011-2014), the new organization was established and assumptions were profoundly challenged. The management team gave power and mandate to employees to take on greater responsibility, the Future Trip was launched, and employees were given a clear mandate to decide new directions in strategy and processes, with a new view on recruitment of managers and leaders based on experience and capacity to lead, rather than academic accomplishments and formal expertise. 


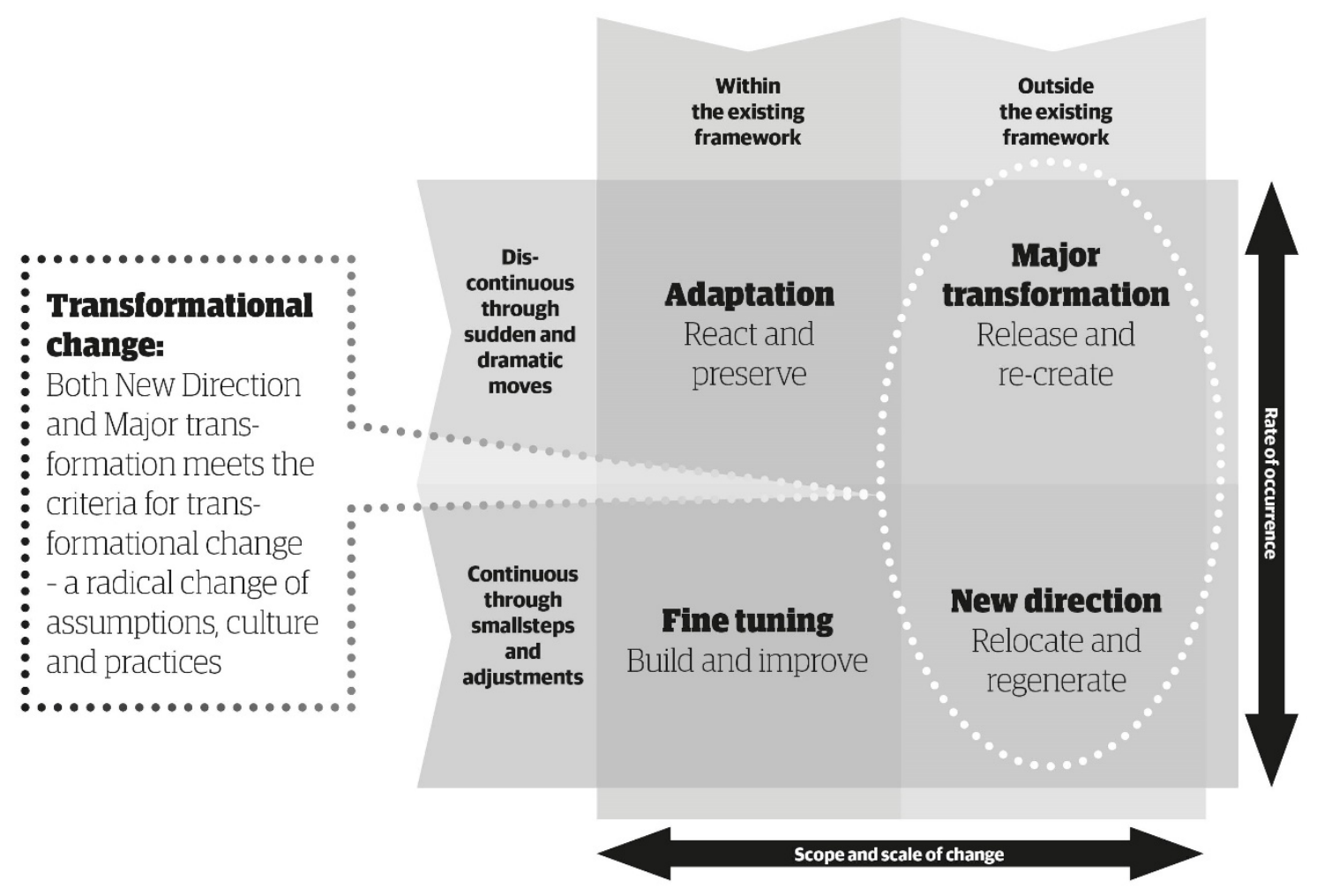

Figure 2. Transformational change. Source: Based on Marshak (2002), Nadler and Nadler (1998), Kezar and Eckel (2002) and Pettigrew (1987).

\section{Discussion}

The analysis of the changes that occurred during a 10-year process showed three types of change ending with transformational change. The discussion is organized according to Pettigrew's (1987) three perspectives of change: context, content and process. These perspectives embrace the complexity and balance of both external contextual factors and the human perspectives and interactions in a transformational change process.

Research indicates that external pressure is necessary to overcome inertia in change (Kotter, 1996; VanDeusen Lukas et al., 2007). The antecedent of this change process was demands for increased productivity and world-class quality. The external pressure in this study was handled with transparency; everybody was aware of the competition within the industry. Several plants in the corporate family had closed, and the risk of closure of the 
Swedish plant was impending. The why of change (Pettigrew, 1987) was clear to everybody, thus creating readiness for change (Kegan and Lahey, 2009; VanDeusen Lukas et al., 2007). Major change takes time and the lack of long-term orientation can be identified as an explanation of failure in change efforts (Eckel et al., 1999; Kezar and Eckel, 2002). When the external pressure increased in 2011 (50\% increase in productivity within 5 years), the support of long-term orientation and a compelling vision and mission created the energy and incentives to carry on (Kezar and Eckel, 2002; Kotter, 1996). The site leader's capacity to look several years ahead and create visionary goals gave time for the necessary changes to be made and energy for new possibilities when a major change was to be made (Joiner and Josephs, 2007; Kotter, 1996). The internal context was an organizational culture prepared for change and people willing to take on challenges in order to sustain the business. The message of urgency was rapidly understood and accepted.

The what of change, initially increased efficiency and productivity, led to the use of quality improvement (QI) tools. They were accepted as tools but after 2 years, people understood on a more systemic level when the results of using the different tools showed in increased efficiency and productivity. Walshe and Freeman (2002) concluded that the outcome of the use of QI tools much depends on the context in which they are adopted and the perseverance in holding on to them. Everybody could see that the improvements created increased efficiency and less waste. Newhouse and Chapman (1996) stressed the importance of internal ambassadors to carry the changed schemes and methods. In our study, trusted internal leaders held on to the QI tools, and new leaders with experience of QI work in other plants joined and provided inspiration in this context. The QI work within the current frames prepared for more dramatic changes, but the leap to more radical changes took years so that people had the time to adapt and accept new schemes (Greenwood and Hinings, 1993; Newhouse and Chapman, 1996; Pettigrew et al., 2001). 
Transformational change is a lengthy process because it must include sense making and a gradual re-evaluation of practices and assumptions (Greenwood and Hinings, 1993; Kezar and Eckel, 2002; Newhouse and Chapman, 1996; Pettigrew et al., 1992). A critical mass of people must be given time to adopt new ways of working and thinking to make change stick (Newhouse and Chapman, 1996; Senior and Swailes, 2010). The findings from the process in our study also resonate with previous research with regard to the sequence of change activities. Amis et al. (2004) claim that the sequence of change is important. Even if the pressure to change is high, the gradual process of change should start with a vital part of the organization to provide an example, but also in a symbolic way to convey the importance of the transition being made (Amis et al., 2004; Pettigrew, 1987). In this study, the more tangible change activities started in one part of the organization, the production and quality departments. They took the lead in seeking collaborative advantages and opportunities to be more efficient by looking at a more systemic level to see if lead times could be shortened and services provided in collaboration to make the work more effective.

The how of change, addressing the actors in the change process, including leadership, not least at the highest level of the organization, is certainly crucial, although not the only factor for success (Pettigrew, 1987). The process of change is much influenced by the leaders' abilities to provide a clear vision, to facilitate sense making and give crucial groups and individuals a clear and adequate mandate to do what they consider best given the circumstances (Kezar and Eckel, 2002; Kotter, 1996; Lee et al., 2012; Newhouse and Chapman, 1996). Trust in employees' capacity and knowledge was present during the tenure of both site leaders (2005-2010 and 2010-2014), and the distribution of power was completed at the end of the second site leader's term. The capacity to endure uncertainty during change and the warmth and personal considerations from the second site leader were mentioned frequently at the interviews and meetings. These leader features resonate with findings within 
the field of adult development and leadership whereby indications about a leader's capacity to lead change and handle complexity indicate a correlation between a leader's level of adult development and their ability to master change (Commons and Ross, 2008; Joiner and Josephs, 2007; Kjellström and Andersson, 2017; Norrman Brandt et al., 2019; Rooke and Torbert, 1998). The role of leadership and the reactions of the employees to the methods and leadership in this process are further presented in Norrman Brandt et al. (2019).

This change process can be described as successful regarding productivity, quality and employee satisfaction (Sandell et al., 2013). It adds in-depth practical knowledge on how this was achieved. Success factors in the process were the visionary, long-term view of the site leaders, which made room for the necessary changes to take place; awareness of external demands; the transparent and yet hopeful communication of the challenges ahead; the involvement of all employees in the efforts to make necessary changes; a change readiness in the organization underpinned by awareness of the competitive context within the pharmaceutical industry; the distribution of power when creating new solutions for the bold changes that had to be made; the trust in employees' knowledge and willingness to handle a critical situation; the courage to challenge old assumptions about power and mandate when creating a new organizational map. In summary, the balance and attention to all the perspectives of a transformational change process made it successful

This article fills a gap in relation to previous studies by providing an empirical example of successful transformational change where the process and the different phases of change are thoroughly described. It relates to theories of transformational change verifying earlier theoretical findings, but also providing a sequence of change phases that can be studied in forthcoming studies of transformational change. 


\section{Implications}

The findings in this paper have several practical implications for change leaders facing transformation. Clear and transparent communication around contextual factors increases awareness and change readiness among all members of the organization. A long-term view is necessary in order to make the space and time for radical changes. Leaders are responsible for creating this awareness in the organization. Transparency and involvement at all levels of the organization as well as sense-making activities seem to be crucial. Expectations on distribution of responsibility as well as distribution of power when and where it is possible also seem to release the full potential of the organization. Adoption of a toolkit that supports the philosophy advocated and holds on to it is helpful. Leading transformational change is not a one-woman or a one-man endeavour. Success depends on the change leader's willingness and ability to collaborate and cooperate with stakeholders. Although this change process takes place in a small organization, the case provides inspiration and courage for change leaders to adopt somewhat unusual methods. The study provides an example of a crisis turned into success.

Implications on a social level are that transformational change means a new way of leading and managing organizations. The pace of change in society has increased the need for transformations calling for new organizational competencies and altered roles. The view on leaders' and employees' roles have to change and the assumptions underpinning hierarchical systems should be abandoned. Further research is needed on transformational change processes to provide leaders and scholars with empirical examples.

\section{References}

Amis, J., Slack, T., and Hinings, C.R. (2004), “The pace, sequence and linearity of radical change", Academy of Management Journal, Vol. 47 No. 1, pp. 15-39. 
Balogun, J. and Hope Hailey, V. (2008), Exploring Strategic Change, 3rd edn, Pearson Education, London.

Balogun, J., Hope Hailey, V, and Gustafsson, S. (2016), Exploring Strategic Change, 4th edn, Pearson Education, Harlow.

Burnes, B. (2009), Managing Change: A Strategic Approach to Organizational Dynamics, Prentice Hall/Financial Times, New York, NY.

Burnes, B. (2011), “Introduction: why does change fail and what can we do about it?”, Journal of Change Management, Vol. 11 No. 4, pp. 445-450.

By, R.T. (2005), “Organizational change management: a critical review”, Journal of Change Management, Vol. 5 No. 4, pp. 369-380.

Cameron, K., Dutton, J. and Quinn, R. (2003), “An introduction to positive organizational scholarship", in Cameron, K., Dutton, J., and Quinn, R. (Eds.), Positive Organizational Scholarship-Foundations of a New Discipline, Berret-Koehler, San Francisco, CA.

Commons, M.L. and Ross, S.N. (2008), "What postformal thought is, and why it matters", World Futures The Journal of New Paradigm Research, Vol. 64 No. 5-7, pp. 321-329.

Cooperrider, D. and Whitney, D. (2005), Appreciative Inquiry: A Positive Revolution in Change, Berret-Koehler, San Francisco, CA.

Crocitto, M. and Youssef, M. (2003), “The human side of organizational agility”, Industrial Management and Data Systems, Vol. 103 No. 6, pp. 388-397.

Eckel, P., Hill, B., Green, M., and Mallon, B. (1999), Taking Charge of Change: A Primer for Colleges and Universities on Change, Occasional Paper No. 3, Americas Council on Education, Washington, DC. 
Eisenhardt, K.M., and Graebner, M.E. (2007), “Theory building from cases: opportunities and challenges", Academy of Management Journal, Vol. 50 No. 1, pp. 25-32.

Ellström, P.E. (2007). “Knowledge creation through interactive research: a learning perspective”, Conference paper HSS-07, Jönköping University.

Elo, S., Kääriäinen, M., Kanste, O., Pölkki, T., Utrainen, K. and Kyngäs, H. (2014), "Qualitative content analysis: a focus on trustworthiness", SAGE Open Vol. 4 No. 1. doi:10.1177/2158244014522633

Friedli, T., Prabir, B., Bellm, D. and Werani, J. (Eds.) (2013), Leading Pharmaceutical Operational Excellence, Outstanding Practices and Cases, Springer, Berlin.

Greenwood, R., and Hinings, C.R. (1988), “Organizational design types, tracks and the dynamics of strategic change", Organization Studies, Vol. 9 No.3, pp. 293-316.

Greenwood, R. and Hinings, C.R. (1993), "Understanding strategic change: the contribution of archetypes", Academy of Management Journal, Vol. 36 No. 5, pp. 725-755.

Hallencreutz, J. (2012), Under the skin of change, meanings, models and management, Doctoral Thesis, Luleå University of Technology.

Hamel, G. (2006), “The why, what and how of management innovation”, Harvard Business Review, Vol. 84 No. 2, pp. 72-84, 163.

Iveroth, E. and Hallencreutz, J. (2015), Effective Organizational Change. Leading Through Sensemaking, Routledge, London and New York.

Joiner, W.B., and Josephs, S.A. (2007), Leadership Agility: Five Levels of Mastery for Anticipating and Change, Jossey-Bass, San Francisco, CA.

Kegan, R. and Lahey, L. (2009), Immunity to Change, Harvard Business Review Press, Boston, MA. 
Kezar, A. and Eckel, P. (2002), "Examining the institutional transformation process: the importance of sensemaking, interrelated strategies, and balance", Research in Higher Education, Vol. 43 No. 3, pp. 295-328.

Kjellström, S. and Andersson, A.-C. (2017), “Applying theories of adult development to improvement science", International Journal of Health Care Quality Assurance, Vol. 39 No. 7, pp. 617-627.

Kotter, J.P. (1996), Leading Change, Harvard Business School Press, Boston, MA.

Kotter, J.P. (2007), A Sense of Urgency, Harvard Business School Press, Boston, MA.

Langley, A. (1999), "Strategies for theorizing from process data", Academy of Management Review, Vol. 24 No. 4, pp. 691-710.

Lant, T.K., Milliken, F.J., and Batra, B. (1992), “The role of managerial learning and interpretation in strategic persistence and reorientation: an empirical exploration", Strategic Management Journal, Vol. 13 No. 8, pp. 585-608.

Lee, S-Y.D., Weiner, B.J., Harrison, M.I. and Belden, C.M. (2012), “'Organizational transformation: a systematic review of empirical research in health care and other industries", Medical Care Research and Review, Vol. 70 No. 2, pp. 115-142.

Marshak, R.J. (2002), "Changing the language of change; how the new contexts and concepts are challenging the way we talk about change", Strategic Change, Vol. 11 No. 5, pp. 279-286.

Miles, M.B. and Huberman, A.M. (1994), Qualitative Data Analysis. An Extended Sourcebook, 2nd edn, Sage, Thousand Oaks, CA.

Nadler, D.A. and Nadler, M.B. (1998), Champions of Change, Jossey-Bass, San Francisco, CA. 
Newhouse, D. and Chapman, I. (1996), “Organizational transformation: a case study of two aboriginal organizations”, Human Relations, Vol. 49 No. 7, pp. 995-1011.

Norrman Brandt, E., Kjellström, S., and Andersson, A.C. (2019), “Transformational change by a post-conventional leader", Leadership and Organizational Development Journal, accepted May 52019 DOI: 10.1108/LODJ-07-2018-0273

Pettigrew, A.M. (1985), The Awakening Giant, Basil Blackwell, Oxford.

Pettigrew, A. (1987), "Context and action in the transformation of the firm", Journal of Management Studies, Vol. 24 No. 6, pp. 649-669.

Pettigrew, A.M. (1998), "Success and failure in corporate transformation initiatives", in R.D. Galliers and W.R.J. Baets (Eds.), Information Technology and Organisational Transformation, Wiley, London, pp. 271-289.

Pettigrew, A.M., Ferlie, E., and McKee, L. (1992), Shaping strategic change: making change in large organizations, The case of the National Health Service, Public Money \& Management, Vol. 12 No. 3, pp. 27-31.

Pettigrew, A.M., Woodman, A.D. and Cameron, K.S (2001), "Studying organizational change and development: challenges for future research, Academy of Management Journal, Vol. 44. No. 4, pp. 697-713.

Reissner, S.C. (2011), "Patterns of stories of organisational change", Journal of Organizational Change Management, Vol. 24 No. 5, pp. 593-609.

Romanelli, E. and Tushman, M.L. (1994), “Organizational transformation as punctuated equilibrium: an empirical test", Academy of Management Journal, Vol. 37 No. 5, pp. $1141-1166$. 
Rooke, D. and Torbert, W.R. (1998), “Organizational transformation as a function of the CEO's developmental stage", Organization Development Journal, Vol. 16 No. 1, pp. $11-28$.

Rosenbaum, D., More, E. and Steane, P. (2018), "Planned organizational change management. Forward to the past? An exploratory literature review", Journal of Organizational Change Management, Vol. 31 No. 2, pp. 286-303.

Sandell, K., Eriksson, J., Eriksson, K., Stigell-Warnstrom, M. and Gjellan, K. (2013), "Continuous improvement: a path towards excellence", in Friedli T., Prabir, B., Bellm, D. and Werani, J. (Eds.) in Leading Pharmaceutical Operational Excellence, Springer, Berlin and Heidelberg, pp. 433-442.

Seller, C and Davis, R. (2013), "From process stabilization to plant network performance", in Friedli T., Prabir, B., Bellm, D. and Werani, J. (Eds), Leading Pharmaceutical Operational Excellence, Springer, Berlin and Heidelberg, pp. 117-130.

Senior, B. and Swailes, S. (2010), Organizational Change, Pearson Education, Harlow.

Södergren, B. (2016), Flaggskeppsfabriken, Vinnova report 1650-3104; VR 2016:07.

Svensson, L., Brulin, G., Ellström, P-E. and Widegren, Ö. (2002, eds), Interaktiv forskning för utveckling av teori och praktik (in Swedish), Arbetsliv i omvandling, 2002:7. ISBN: 91-7045-637-2.

Taylor, S. (1999), "Making sense of revolutionary change: differences in members' stories”, Journal of Organizational Change Management, Vol. 12 No. 6, pp. 524-539.

Torbert, W.R., Fisher, D. and Rooke, D. (2004), Action Inquiry: The Secret of Timely and Transforming Leadership, Berett-Koehler, San Francisco, CA. 
Tushman, M.L., and Romanelli, E. (1985), “Organizational evolution: a metamorphosis model of convergence and reorientation", in Cummings, L.L. and Staw, B.M. (Eds.), Research in Organizational Behavior, Vol. 7, JAI Press, Greenwich, CT, pp. 171-222.

Van de Ven, A.H. and Poole, M.S. (1995), “Explaining development and change in organizations", Academy of Management Review, Vol. 20 No. 3, pp. 510-540.

VanDeusen Lukas, C., Holmes, S.K., Cohen, A.B., Restuccia, J., Cramer, I.E., Schwartz, M., and Charns, M.P. (2007), "Explaining development and change in organizations", Health Care Management Review, Vol. 32 No. 4, pp. 309-320.

Walshe, K. and Freeman, T. (2002), "Effectiveness of quality improvement: learning from evaluations", Quality and Safety in Health Care, Vol. 11 No. 1, pp. 85-87.

Weick, E.K. and Quinn, E.R. (1999), “Organizational change and development”, Annual Review of Psychology, Vol. 50, pp. 361-386.

Yin, R.K. (2003) Case Study Research: Design and Methods, Sage, Thousand Oaks, CA. 